\title{
Equatorial F-region plasma depletion drifts: latitudinal and seasonal variations
}

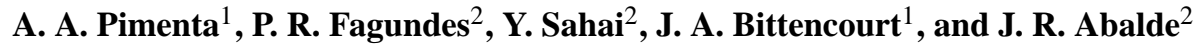 \\ ${ }^{1}$ Instituto Nacional de Pesquisas Espaciais - INPE - C.P. 515, 12201-970, São José dos campos, SP, Brazil \\ ${ }^{2}$ Universidade do Vale do Paraba - UNIVAP, Av. Shishima Hifumi 2911, São José dos Campos, SP, Brazil
}

Received: 10 December 2002 - Revised: 8 April 2003 - Accepted: 17 April 2003

\begin{abstract}
The equatorial ionospheric irregularities have been observed in the past few years by different techniques (e.g. ground-based radar, digisonde, GPS, optical instruments, in situ satellite and rocket instrumentation), and its time evolution and propagation characteristics can be used to study important aspects of ionospheric dynamics and thermosphere-ionosphere coupling. At present, one of the most powerful optical techniques to study the largescale ionospheric irregularities is the all-sky imaging photometer system, which normally measures the strong Fregion nightglow $630 \mathrm{~nm}$ emission from atomic oxygen. The monochromatic OI $630 \mathrm{~nm}$ emission images usually show quasi-north-south magnetic field-aligned intensity depletion bands, which are the bottomside optical signatures of largescale F-region plasma irregularities (also called plasma bubbles). The zonal drift velocities of the plasma bubbles can be inferred from the space-time displacement of the dark structures (low intensity regions) seen on the images. In this study, images obtained with an all-sky imaging photometer, using the OI $630 \mathrm{~nm}$ nightglow emission, from Cachoeira Paulista $\left(22.7^{\circ} \mathrm{S}, 45^{\circ} \mathrm{W}, 15.8^{\circ} \mathrm{S}\right.$ dip latitude), Brazil, have been used to determine the nocturnal monthly and latitudinal variation characteristics of the zonal plasma bubble drift velocities in the low latitude $\left(16.7^{\circ} \mathrm{S}\right.$ to $\left.28.7^{\circ} \mathrm{S}\right)$ region. The east and west walls of the plasma bubble show a different evolution with time. The method used here is based on the western wall of the bubble, which presents a more stable behavior. Also, the observed zonal plasma bubble drift velocities are compared with the thermospheric zonal neutral wind velocities obtained from the HWM-90 model (Hedin et al., 1991) to investigate the thermosphere-ionosphere coupling. Salient features from this study are presented and discussed.
\end{abstract}

Key words. Ionosphere (ionosphere-atmosphere interactions; ionospheric irregularities; instruments and techniques)

Correspondence to: A. A. Pimenta (pimenta@laser.inpe.br)

\section{Introduction}

During recent years, all-sky imaging photometers have provided several key pieces of information related to the spacetime evolution of gravity waves and large-scale ionospheric irregularities at mesospheric and thermospheric/ionospheric heights, respectively. The nightglow emissions that come from F-region heights (e.g. OI $777.4 \mathrm{~nm}$, OI $630 \mathrm{~nm}$ and OI $557.7 \mathrm{~nm}$ ) are used in connection with studies of traveling ionospheric disturbances, dynamics of the equatorial ionospheric anomaly, dynamics related to the thermospheric midnight temperature maximum, thermosphere/ionosphere coupling and equatorial F-region ionospheric irregularities (Biondi et al., 1999; Bittencourt et al., 1997; Colerico et al., 1996; Moore et al., 1981; Pimenta et al., 2001a; Rohrbaugh et al., 1989; Sahai et al., 1981; Tinsley et al., 1982, 1997). The OI $630 \mathrm{~nm}$ emission is produced at the bottomside of the ionospheric F-region, at about 250 to $300 \mathrm{~km}$ altitude, by the dissociative recombination process:

$\mathrm{O}_{2}^{+}+e \rightarrow \mathrm{O}+\mathrm{O}^{*}\left({ }^{1} \mathrm{D}\right), \mathrm{O}^{*}\left({ }^{1} \mathrm{D}\right) \rightarrow \mathrm{O}+h v(\lambda=630 \mathrm{~nm})$

and is commonly used to investigate the thermospheric/ionospheric processes at F-region heights.

Equatorial F-region irregularity studies using a monochromatic (OI $630 \mathrm{~nm}$ emission) all-sky imaging photometer system were first conducted by Weber et al. (1978). Their observations, in the equatorial region, showed the presence of quasi-north-south magnetic field-aligned airglow depletions, with east-west scale sizes ranging from 40 to $450 \mathrm{~km}$, usually drifting eastward, and the plasma bubble drift velocities were fairly close to the zonal ambient plasma drift velocities (Woodman, 1972; Zalesak et al., 1982). The OI $630 \mathrm{~nm}$ emission intensity depletions, or dropouts, are the bottomside optical signatures of equatorial F-region plasma bubbles, and the plasma drift velocities constitute an important parameter for thermosphere-ionosphere coupling studies.

The earlier attempts to calculate the eastward plasma bubble drift velocities, using an all-sky imaging photometer system, were carried out by superposing an appropriate grid on 

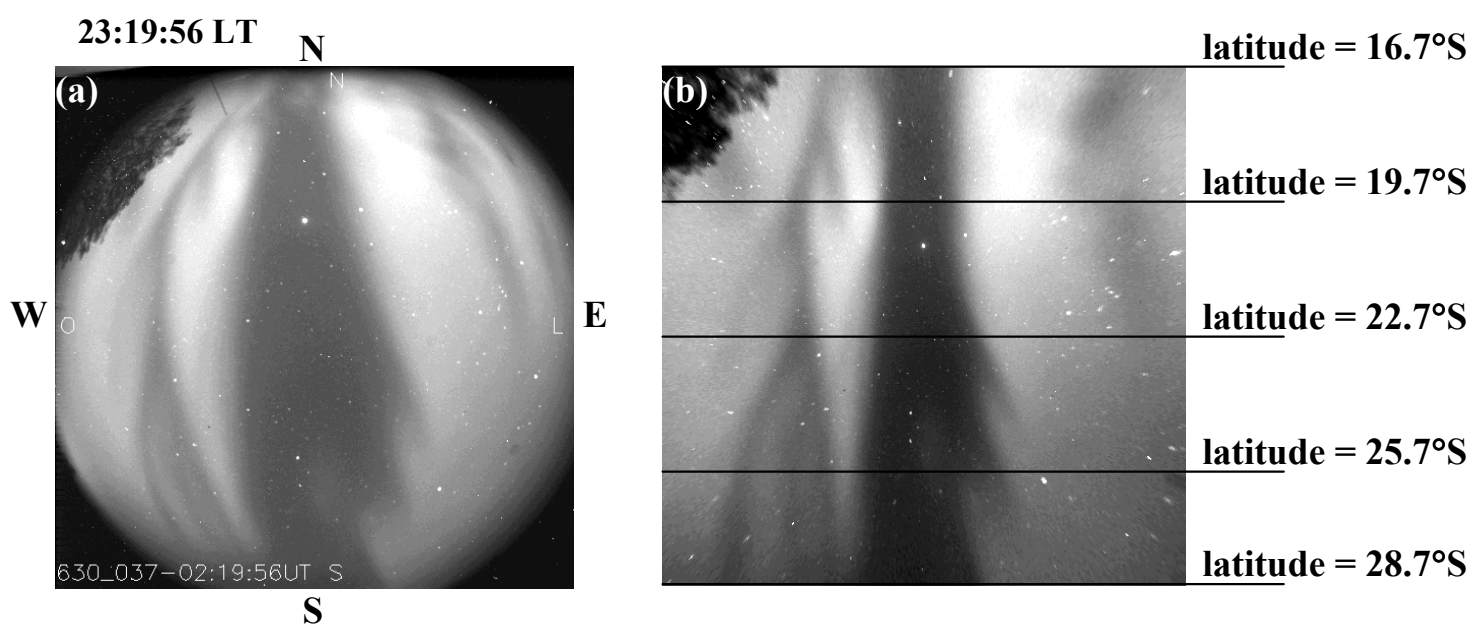

Fig. 1. (a) Ionospheric irregularity (plasma bubble) structures observed by means of the OI $630 \mathrm{~nm}$ airglow emission. Data were recorded from Cachoeira Paulista, Brazil, on 2 November 1999 at 23:19:56 LT. (b) Linearized image (original shown in (a)) corresponding to a mapped area of the processed image of $1320 \mathrm{~km} \times 1320 \mathrm{~km}$ of the OI $630 \mathrm{~nm}$ airglow emission layer, assuming a peak emission altitude of $250 \mathrm{~km}$.

the recorded OI $630 \mathrm{~nm}$ emission images (Weber et al., 1978; Mendillo and Baumgardner, 1982; Fagundes et al., 1997). Afterwards, using digitalized images of the OI $630 \mathrm{~nm}$ emission, Mendillo et al. (1997a) and Taylor et al. (1997) presented a technique, which improved the calculations of the plasma bubble drift velocities. In their technique, initially the bi-dimensional images are scanned in the east-west direction (through the zenith), in order to obtain a slice of each image and to provide one-dimensional east-west intensity variations. Then, using successive images, the intensity scans through the zenith are subjected to a cross-correlation analysis, to obtain the eastward plasma bubble drift velocities. More recently, Pimenta et al. (2001b) first linearized the OI $630 \mathrm{~nm}$ emission images using an appropriate geographic coordinate system and, after that, compared the east-west intensity variations in consecutive image slices to obtain the eastward plasma bubble drift velocities. They observed that the space-time dynamics of the plasma bubbles led to changes in their shapes and dimensions, which may induce errors in the calculated plasma drift velocities. Pimenta et al. (2001b) discussed the different dynamic behavior observed between the eastern and western walls of the intensity depletions, as seen in the OI $630 \mathrm{~nm}$ emission linearized images. In this paper, we present and discuss the latitudinal and seasonal variations of the eastward plasma bubble drift velocities inferred using the technique described in detail by Pimenta et al. (2001b).

\section{Instrumentation and data analysis}

All-sky monochromatic/multi-spectral wide-angle imaging systems have been used for aurora and airglow studies during recent decades, with great success. There has been considerable improvement in their capabilities to observe very faint and low contrast nightglow emissions, due to recent advances in CCD detectors (Mendillo et al., 1997b; Garcia et al., 1997; Taylor et al., 1997; Abalde et al., 2001; Pimenta et al., 2001b; Santana et al., 2001). The images recorded with the all-sky imaging system (from the Utah State University, Taylor et al., 1997) which carried out regular observations at Cachoeira Paulista $\left(22.7^{\circ} \mathrm{S}, 45.0^{\circ} \mathrm{W} ; 15.8^{\circ} \mathrm{S}\right.$ dip latitude), Brazil, since 1998, provided time evolution and spatial variations of selected atomic or molecular emissions over a wide sky area. Since the emission layers are originated at quasi-fixed heights, with a range of altitude varying from 10 to $50 \mathrm{~km}$, it is possible to study the dynamics and spatial-temporal variations of irregularities that occur in this particular height region.

The imaging system used to record the space-time nightglow variations, in the present study, has a large CCD area $\left(6.45 \mathrm{~cm}^{2}\right)$, with high resolution and a $1024 \times 1024$ backilluminated array having a pixel depth of 14 bits. The images have been binned on-chip down to a $512 \times 512$ resolution, to enhance the signal-to-noise ratio and are recorded at intervals of $7 \mathrm{~min}$, with a 90-s exposure time rate.

Figure 1a shows an example of the OI $630 \mathrm{~nm}$ emission image recorded at Cachoeira Paulista. The quasi-north-south magnetic field-aligned airglow depletions (dark structures) seen in the image are the optical signatures of the plasma bubbles. It is noted that the image appears curved and compressed at low elevation angles (image edge), and the image is inflated at high elevation angles (around zenith). Thus, the raw image is distorted with respect to the radius. In order to calculate the east-west drift velocities of the plasma bubbles, as a function of local time, we first transform the raw image into a geographic grid image (Cartesian coordinate system), using the linearization method described by Garcia et al. (1997). Figure 1b shows an example of the transformed image, after being linearized. Notice that the processed image area is $1320 \mathrm{~km} \times 1320 \mathrm{~km}$, assuming that the OI $630 \mathrm{~nm}$ peak emission layer is at $250 \mathrm{~km}$. In this figure, it is possible to see the quasi-north-south magnetic field-aligned plasma 
Red 23:56:59 LT

Blue 00:11:15 LT

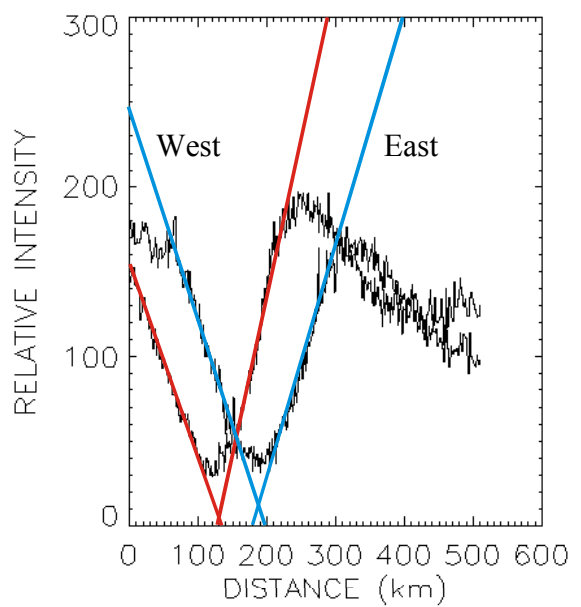

Red 23:56:59 LT

Blue 00:25:32 LT

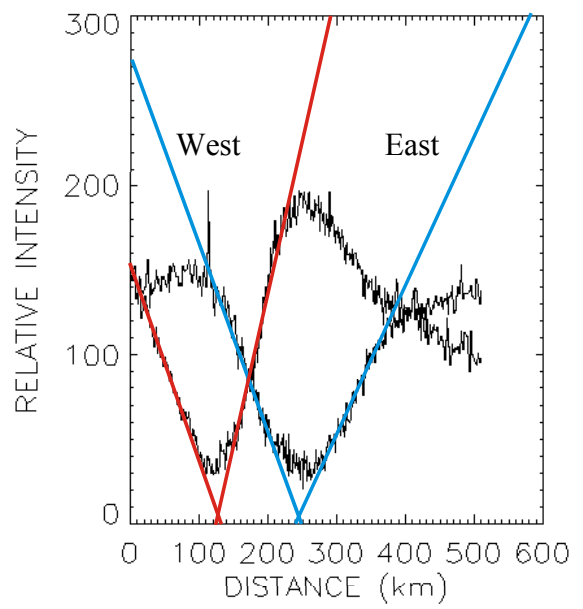

Red 23:56:59 LT

Blue 00:18:23 LT

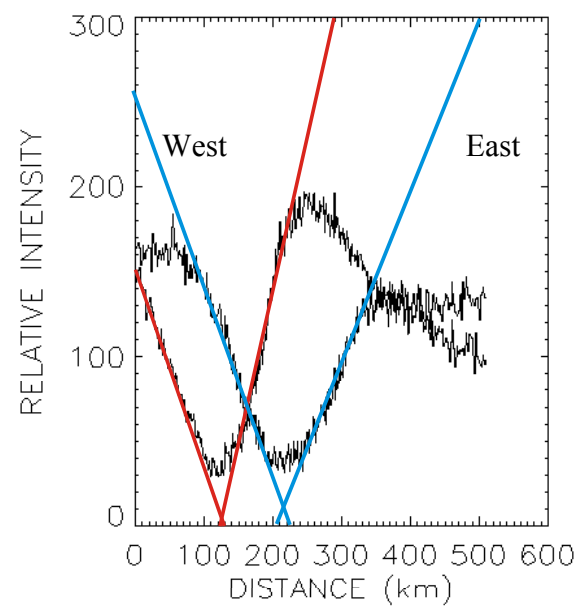

Red 23:56:59 LT

Blue 00:54:04 LT

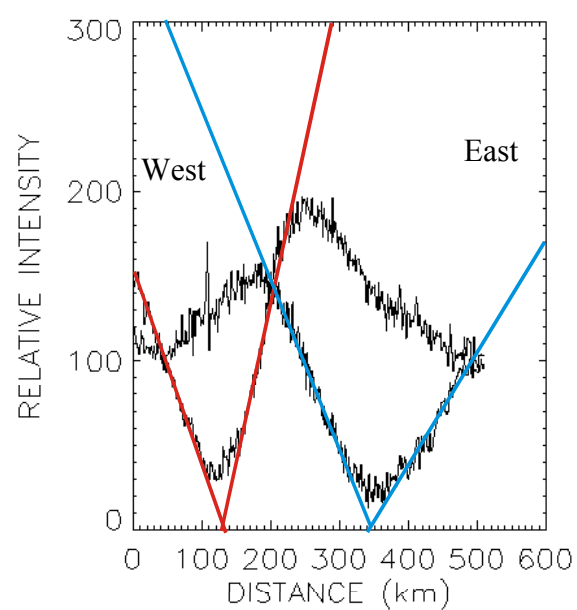

Fig. 2. East-west intensity scans, through zenith, of five consecutive images (lineralized images corresponding to a mapped area of the processed image of $600 \mathrm{~km} \times 600 \mathrm{~km}$ of the OI $630 \mathrm{~nm}$ airglow emission layer, assuming an emission altitude of $250 \mathrm{~km}$ ) observed on 1-2 January 2000, illustrating the different dynamic behavior observed between the east (right side) and west (left side) walls of the intensity depletions. The red lines are east-west scan obtained at 23:56:59 LT and repeated in all the panels. The blue lines are the east-west scans obtained at different times indicated in the panels.

bubble characteristic in a more pronounced way, and it permits more precise calculations of the plasma bubble drift velocities. Also, this image allows for the calculation of the plasma bubble drift velocities at several latitudes, by taking intensity scans in the east-west direction. From the analysis of consecutive processed images (in the Cartesian grid), it is possible to determine the time variations of the zonal plasma drift velocities at several latitudes, as shown in Figs. 1b and 2.

The irregularities characterized by large-scale F-region plasma depletions (plasma bubbles) extend several thousands of kilometers across the magnetic equator, with east-west dimensions ranging from a few tens of kilometers to a few hundred kilometers, with fine structures in the range of a few kilometers. It should be mentioned that the OI $630 \mathrm{~nm}$ imaging observations provide a two-dimensional bottomside view (dark structures in Fig. 1) of the ionospheric bubbles that extend into the topside ionosphere and across the entire equatorial region (Weber et al., 1980). From the spatial displacements of the dark structures, during successive images, we can infer the irregularity zonal drift velocities, which are closely related to the ionospheric zonal plasma drift velocities. Also, the nighttime ionospheric plasma drift velocities in the equatorial region are approximately equal to the thermospheric zonal winds (Rishbeth, 1971; Biondi et al., 1988).

The plasma bubbles, which generally drift toward the east, have their own internal space-time dynamics, leading to changes in their shapes, dimensions and wall structure/gradient. These structural variations with time may lead to errors in the calculated zonal drift velocities. Using radar 


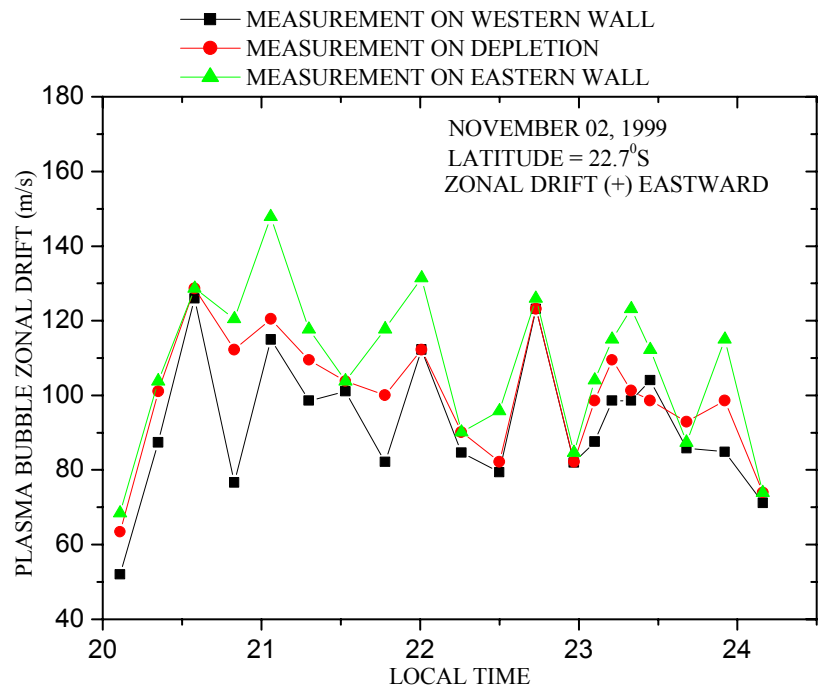

Fig. 3. Zonal plasma drifty velocities calculated using either the displacement of the center of the depletion, or the eastern wall, or the western wall of the plasma bubble.

backscatter observations, Tsunoda (1983) has reported structures of the west walls (upwelling) of plasma bubbles by the wind-driven gradient drift instability. Mendillo and Baumgardner (1982) have presented results of the OI $630 \mathrm{~nm}$ allsky imaging observations of the plasma bubbles and reported that the intensities, within depletions (dark structures), were typically $40-50 \%$ of the background levels. They also reported that the western walls of the depletions usually had a steeper gradient than the corresponding eastern walls.

Figure 2 presents a sequence of four east-west intensity scans, through zenith, of the linearized image slices for about $1 \mathrm{~h}$, between 23:57 to 00:54 LT on 1-2 January 2000. The red lines are the east-west scans obtained at 23:56:59 LT (e.g. see Fig. $1 \mathrm{~b}$ for latitude $22.7^{\circ} \mathrm{S}$ ). The blue lines are the east-west scans obtained at consecutive times, as indicated in Fig. 2. From a perusal of the four panels (Fig. 2), it is clearly noticed that the inclination (density gradient) of the western wall does not change with time (it has a relatively stable structure), whereas the inclination, or density gradient, of the eastern wall changes with time, indicating that the bottomside of the plasma bubble, as seen by the OI $630 \mathrm{~nm}$ emission, becomes broader and broader on the eastern side. The observed plasma bubble wall structures are similar to those reported by Mendillo and Baumgarder (1982), with the western wall of the depletion having a steeper gradient than the corresponding eastern wall. The changes in shape of the eastern wall could be associated with the strong thermosphereionosphere coupling which takes place in the bottomside of the F-region. Therefore, an approach to obtain the time variation of the plasma drift velocities, based on the western wall, reduces the effects due to the internal space-time dynamics of the plasma bubble, since the OI $630 \mathrm{~nm}$ emission intensity gradient, at the western wall, is more stable than the corresponding gradient at the eastern wall.

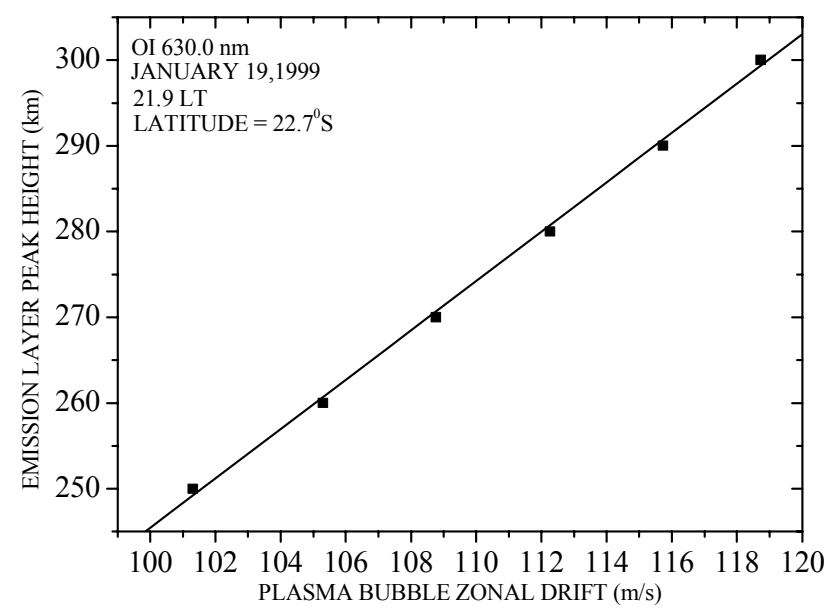

Fig. 4. Calculated zonal plasma bubble drift velocities using the same set of linearized images, but assuming the OI $630 \mathrm{~nm}$ emission peak height at different altitudes.

In the present study we have used the time-displacements of the western walls of the plasma bubbles to estimate the plasma drift velocities. Figure 3 shows a comparison of the local time variations of the zonal plasma drift velocities inferred from the plasma bubbles on the night of 2-3 November 1999, using either the time-displacements of the western walls, or the minimum level of the intensity depletions, or the eastern walls. The methodology is based on Pimenta et al. (2001b). It is observed, from Fig. 3, that the local time variations of the plasma drift velocities, using the three different approaches, are fairly similar, but the velocities inferred differ significantly (the drift velocities obtained from the minimum depletion intensities are about 10\%-20\% higher than those obtained from the western walls, whereas the difference increases to about $40 \%$ between those inferred from the western walls and from the eastern walls).

Also, we have considered that the OI $630 \mathrm{~nm}$ emission peak height is located at $250 \mathrm{~km}$. However, during the course of a night the OI $630 \mathrm{~nm}$ peak emission height undergoes changes around $250 \mathrm{~km}$, due to the F-layer peak height variations. In Fig. 4 we present the changes in the plasma drift velocities for different OI $630 \mathrm{~nm}$ emission peak heights. It is observed that, if the OI $630 \mathrm{~nm}$ emission peak height is considered as $300 \mathrm{~km}$, instead of $250 \mathrm{~km}$, the plasma drift velocities increase by about $20 \%$.

\section{Results and discussion}

\subsection{Zonal plasma drift}

The occurrence of plasma bubbles, in the period MayAugust (winter-time in the Southern Hemisphere), is a very rare phenomenon over the Brazilian sector (Sahai et al., 2000; Pimenta et al., 2001a). Thus, average monthly lati- 
Table 1. Observations around equinox and summer during moderate-to-high solar activity (October-March, between the years 1998-2000)

\begin{tabular}{cccc}
\hline Month & \# of nights of observations & \# of nights of bubble occurrences & Average solar flux (F10.7) \\
\hline October & 7 & 5 & 141 \\
November & 9 & 5 & 166 \\
December & 7 & 6 & 160 \\
January & 10 & 9 & 150 \\
February & 6 & 6 & 158 \\
March & 10 & 7 & 150 \\
Total & 49 & 38 & \\
\hline
\end{tabular}

tudinal and nighttime variations of the plasma drift velocities can only be studied during the period from October to March. The period and conditions of the observations studied in the present investigation correspond to geomagnetic quiet conditions and moderate-to-high solar activity. Table 1 shows the details of the observations during the months studied, when strong plasma bubble occurrences are normally present, as mentioned earlier (periods October-March, between the years 1998 to 2000).

The observed average latitudinal and nighttime monthly zonal plasma drift velocities, from October to March, are shown as contour maps in Fig. 5. The nocturnal variation patterns, for all months, show high eastward drift velocities in the evening hours (20:00 to 22:00 LT), with the velocities decreasing gradually after 22:00 LT. However, the zonal plasma drift velocities and their latitudinal distributions are different for each month, characterizing monthly changes. The maximum zonal drifts velocities are observed during the evening hours, having higher values $(>150 \mathrm{~m} / \mathrm{s})$ during the months of January, February and March, and, in general, such large velocities are in the northward sector of the observation site. As we move from October to February, the maximum velocity locations move to southward and higher velocities have longer durations. During the month of March, the velocity variations are again similar to the October conditions.

Figure 6 shows contour maps of the zonal neutral wind velocities obtained from the HWM-90 model (Hedin et al., 1991), for the same latitude region and months for which data are presented in Fig. 5, in order to compare their magnitudes and shapes with the observed zonal drift velocities. It is noted that both the monthly and nocturnal variations are very similar.

Sahai et al. (1992) have reported observations of zonal neutral wind velocities at Cachoeira Paulista, for the period March, 1988-December, 1989. The winds are eastward throughout the night, for all the seasons, and are stronger during the early part of the night. The nocturnal variations show a monotonic decrease after midnight. The average solar activity for the present plasma bubble drift velocity observations is very similar to that of the zonal neutral wind velocity observations presented by Sahai et al. (1992). A comparison of the zonal neutral wind velocities inferred at C. Paulista (Sahai et al., 1992) and the plasma bubble zonal drift velocities, inferred in the present work, for equinox and summer periods, shows that both the nocturnal variations and the magnitudes are fairly similar.

Figures 5 and 6 give clear indications that the observed zonal plasma bubble drift velocities and the zonal neutral wind velocities (HWM-90 model) have similar latitudinal and nighttime variations and this confirms the suggestion, from theoretical considerations, that the nighttime zonal plasma drift velocities, near the equator, are approximately equal to the F-region neutral zonal winds (Biondi et al., 1988). The zonal F-region wind dynamo drives the Pedersen currents and creates a vertical polarization electric field, which forces the plasma to drift at nearly the same velocity as the neutral wind velocity (Rishbeth et al., 1971). On the other hand, the results reported in Fig. 5 supplement the Biondi et al. (1999) by extending the measurements into the summer season. The results of this work suggest that the strong coupling between the thermosphere and the ionosphere takes place not only in equatorial region, as proposed earlier, but it also extends to low latitude regions, including the equatorial ionospheric anomaly region.

\subsection{Plasma bubble wall dynamics}

As mentioned before, plasma bubbles are F-region largescale irregularities that are quasi-north-south magnetic fieldaligned (see Fig. 1). The electron density in a plasma bubble is substantially lower than the ambient ionospheric electron density. The plasma bubble walls, considered here, are the regions where there are strong plasma density gradients (see Fig. 2), separating the inside and the outside of the plasma bubble structures. In an effort to find the best way to correctly infer the plasma bubble drift velocities, using the OI $630 \mathrm{~nm}$ emission, we have investigated the differences in the time evolution of the plasma bubble walls, as seen through the $630 \mathrm{~nm}$ emission.

The lifetime of the atomic oxygen excited state $\mathrm{O}\left({ }^{1} \mathrm{D}\right)$, from which the OI $630 \mathrm{~nm}$ emission originates, is approximately 110 seconds, which is relatively large. Therefore, the OI $630 \mathrm{~nm}$ emission images will show blurring effects, due to $\mathrm{O}\left({ }^{1} \mathrm{D}\right)$ diffusion, and spatial structures of the order of $30 \mathrm{~km}$ or less will not be perceptible. However, it is expected that the blurring effects will be equally experienced by both the western and eastern walls of the plasma bubble and, therefore, the above mentioned progressive variation of the incli- 


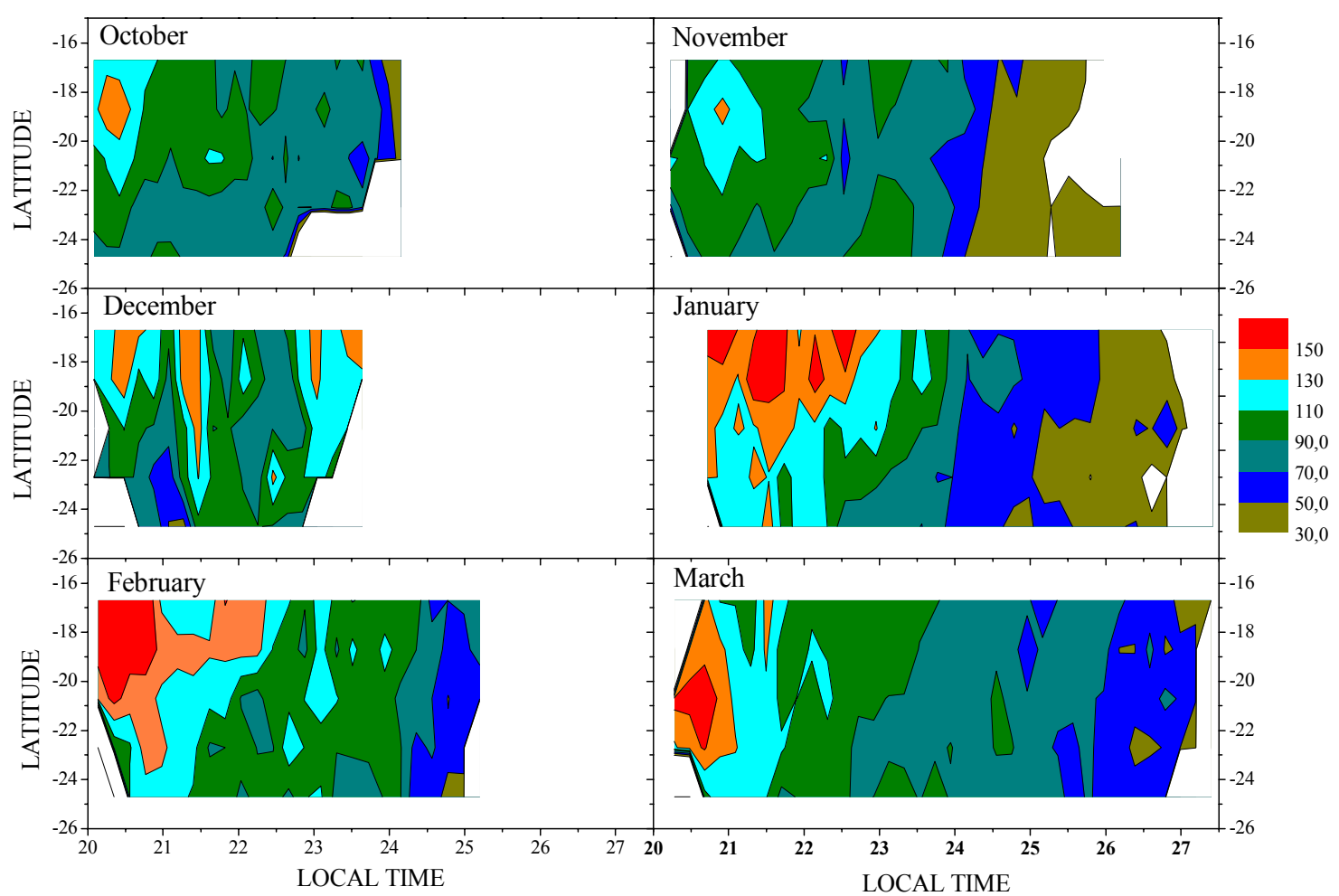

Fig. 5. Contour maps showing latitudinal monthly zonal plasma drift velocity variations, as a function of local time, during geomagnetically quiet conditions for moderate-to-high solar activity.

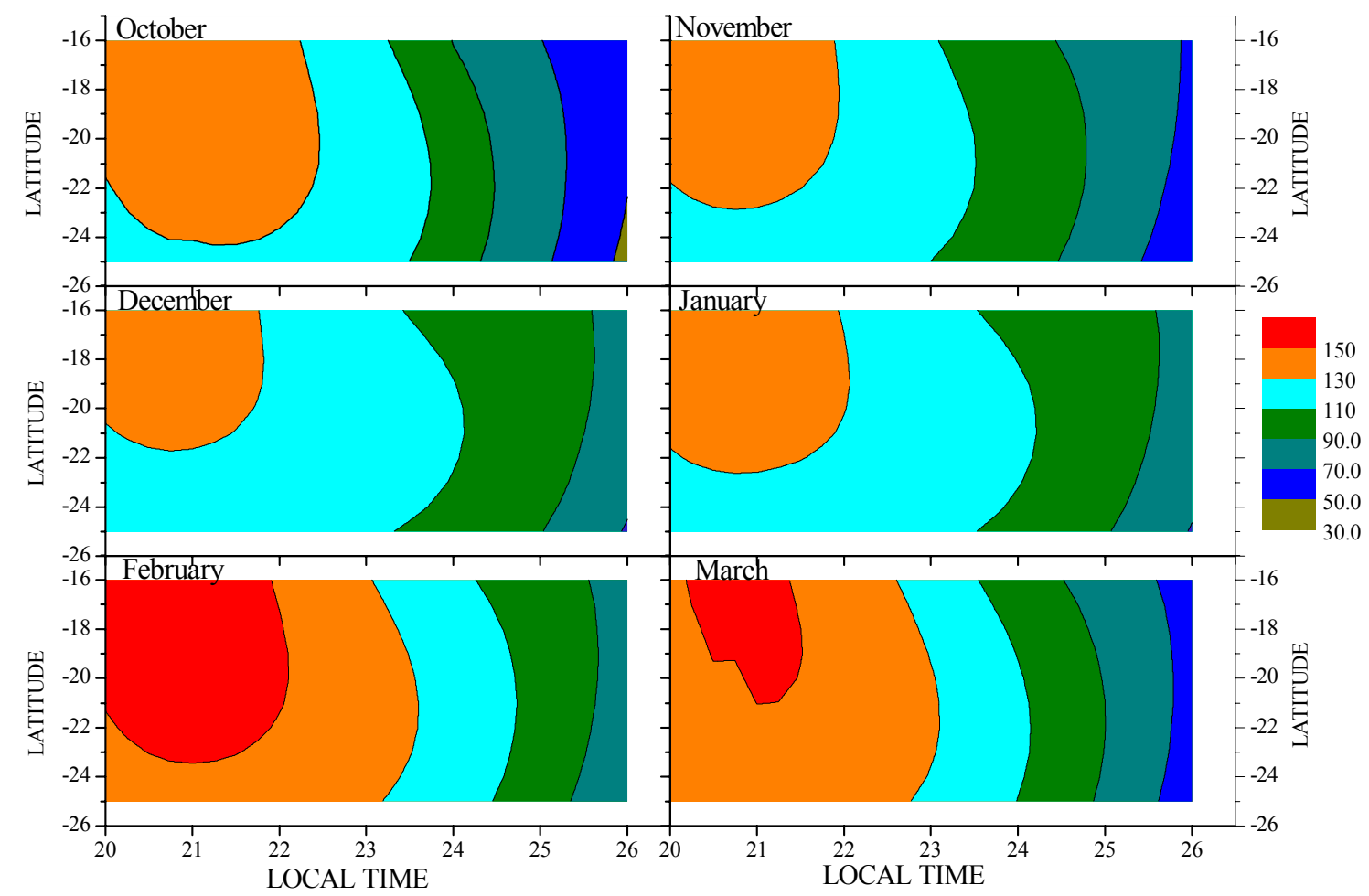

Fig. 6. HWM-90 output model maps showing latitudinal and nighttime neutral zonal wind velocity variations, for October to March, during high solar activity conditions. 
nation (density gradient) of the eastern wall is not related to the relatively large lifetime of the $\mathrm{O}\left({ }^{1} \mathrm{D}\right)$ atoms.

It should be pointed out that, at nighttime, both the thermospheric zonal neutral winds and the F-region plasma usually blow eastward, with nearly similar velocities. However, reduced plasma density inside the bubble decreases the ionneutral interaction, which may result in slightly higher neutral wind velocities inside the bubble. Therefore, it is possible that the leading edge of the plasma bubble (eastern wall) undergoes a more strong interaction with the flowing neutral atmosphere. The extra momentum transfer from the wind to the plasma, at the eastern wall, may contribute to the widening of the plasma bubble on the eastern side, which is reflected as the progressive variation in the eastern wall inclination. Also, this strong interaction at the eastern wall possibly contributes in the decay phase of a plasma bubble and its lifetime.

It is felt that simultaneous all-sky imaging observations of the F-region emissions OI $777.4 \mathrm{~nm}$ (which peaks at the Fregion peak height) and OI $630 \mathrm{~nm}$ (about one scale-height below the F-region peak), as well as measurements of thermospheric neutral winds (both zonal and meridional), will be important for a better understanding of the plasma bubble onset, evolution, dynamics and decay.

\section{Conclusions}

Using a methodology proposed by Pimenta et al. (2001b), zonal plasma bubble drift velocities were inferred using OI $630 \mathrm{~nm}$ emission images. The plasma bubble drift velocities are about the same as the velocity of the ambient plasma. The methodology used improves the precision of the zonal drift velocities inferred, by taking into account the plasma bubble shape and its dimension variations. Also, it has been shown that the west wall of the plasma bubble is the best segment to be used as a reference to calculate the plasma bubble displacements. The observations reported here were carried out at low latitudes in Brazil, during moderate-to-high solar activity and quiet geomagnetic conditions. These results show that the latitudinal range covered by the all-sky imaging system is very useful for zonal plasma drift latitudinal variation studies. Further analysis of the database considered is being continued, to yield valuable information related to thermosphere/ionosphere structure and dynamics. The principal features of the present investigation are summarized below. The east and west walls of the plasma bubbles present a different evolution with time. The time evolution of the west wall shows only small changes in its inclination (density gradient), whereas the time evolution of the east wall shows large changes in its inclination.

1. The zonal plasma bubble drift velocities are eastward throughout the night, during all the months studied.

2. The latitudinal and nocturnal variations, for all the months, show high eastward plasma bubble drift velocities in the evening hours (20:00-22:00 LT). The maxi- mum eastward drift velocity is about $170 \mathrm{~m} / \mathrm{s}$ and occurs at 20:40 LT in summer at about $18^{\circ} \mathrm{S}$. After midnight, the eastward plasma bubble drift velocities decrease for both seasons (equinox and summer), but during equinox they reach lower velocities than in summer.

3. The observed zonal plasma bubble drift velocities and the zonal neutral wind velocities, obtained from the HWM-90 model, show similar patterns, indicating a strong thermosphere/ionosphere coupling at low latitudes, including the equatorial ionospheric anomaly region.

Acknowledgements. The authors acknowledge the Fundação de Amparo à Pesquisa do Estado de São Paulo (FAPESP) for the support received through processes 97/13069-4, 95/09207-1 and 98/09892-0, and the Conselho Nacional de Desenvolvimento Cientfico e Tecnológico (CNPq) through process 300955/93-6. US Nation Science Foundation Grant ATM-9525815 supported part of the all-sky imager and nightglow measurements reported here. We thank Dr. H. Takahashi for the all-sky imaging data.

Topical Editor M. Lester thanks a referee for his help in evaluating this paper.

\section{References}

Abalde, J. R., Fagundes, P. R., Bittencourt, J. A., and Sahai, Y.: Observations of equatorial F-region plasma bubbles using simultaneous OI $777.4 \mathrm{~nm}$ and OI $630.0 \mathrm{~nm}$ imaging: New results, J. Geophys. Res., 30331-30336, 2001.

Biondi, M. A., Meriwether, J. W., Fejer, B., Woodman, R.: Measurements of The Dynamics and Coupling of the Equatorial Thermosphere and the F-Region Ionosphere in Peru, J. Atmos.Terr. Phy., 50, 937-942, 1988.

Biondi, M. A., Sazykin, S. Y., Feger, B. G., and Fesen, C. G.: Equatorial and low latitude thermospheric winds: Measured quiet time variations with season and solar flux from 1980 to 1990, J. Geophys. Res., 104, 17 091-17 106, 1999.

Bittencourt, J. A., Sahai, Y., Fagundes, P. R., and Takahashi, H.: Simultaneous observations of equatorial F-region plasma depletions and thermospheric winds, J. Atmos. Terr. Phys., 59, 10491059, 1997.

Colerico, M., Mendillo, M., Nottingham, D., Baumgardner, J., Meriwether, J., Mirick, J., Reinisch, B. W., Scali, J. L., Fesen, C. G., and Biondi, M. A.: Coordinated measurements of F region dynamics related to the thermospheric midnight temperature maximum, J. Geophys. Res., 101, 26 783-26794, 1996.

Fagundes, P. R., Sahai. Y., Batista, I. S., Bittencourt, J. A., and Abdu, M. A.: Vertical and zonal equatorial F-region plasma bubble velocities determined from OI $630 \mathrm{~nm}$ nightglow imaging, Adv. Space Res., 6, 1297-1300, 1997.

Garcia, J. F., Taylor, J. M., and Kelley, M. C.: Two-dimensional spectral analysis of mesospheric airglow image data, Applied Optics, 36, 29, 7374-7385, 1997.

Hedin, A. E., Biondi, M. A., Burnside, R. G., Hernandez G., Johnson, R. M., Killeen, T. L., Mazaudier, C., Meriwether, J. W., Salah, J. E., Sica, R. J., Smith, R. W., Spencer, N. W., Wickwar, V. B., and Virdi, T. S.: Revised Global-Model Of Thermosphere Winds Using Satellite And Ground-Based Observations, J. Geophys. Res., 96, 7657-7688, 1991. 
Mendillo, M. and Baumgardner, J.: Airglow characteristics of equatorial plasma depletions, J. Geophys. Res., 87, 7641-7652, 1982.

Mendillo, M., Baumgardner, J., Colerico, M., and Nottingham, D.: Imaging science contributions to equatorial aeronomy: initial results from the MISETA program, J. Atmos. Solar-Terr. Phys. 59, 1587-1599, 1997a.

Mendillo, M., Baumgardner, J., Nottingham, D., Aarons, J., Reinisch, B., Scali, J., and Kelley, M.: Investigations of thermospheric-ionospheric dynamics with $630 \mathrm{~nm}$ images from the Arecibo observatory, J. Geophys. Res., 102, 7331-7344, 1997b.

Moore, J. G. and Weber, E. J.: OI 6300 and $7774 \sum$ airglow measurements of equatorial plasma depletions, J. Atmos. Terr. Phy., 43(8), 851-858, 1981.

Pimenta, A. A., Fagundes, P. R., Bittencourt, J. A., and Sahai, Y.: Relevant aspects of equatorial plasma bubbles under different solar activity conditions, Adv. Space Res., 27, 1213-1218, 2001a.

Pimenta, A. A., Fagundes, P. R., Bittencourt, J. A., Sahai, Y., Gobbi, D., Taylor, M. J., and Takahashi, H.: Ionospheric plasma bubble zonal drift: A methodology using OI $630 \mathrm{~nm}$ all-sky imaging systems, Adv. Space Res., 27, 1219-1224, 2001 b.

Rishbeth, H.: Polarization Fields Produced by Winds in Equatorial F-Region, Planet. Space Sci., 19, 357, 1971.

Rohrbaugh, R. P., Hanson, W. B., Tinsley, B. A., Cragin, B. L., McClure, J. P., and Broadfoot, A. L.: Images of transequatorial bubbles based on field-aligned airglow observations from Haleakata in 1984-1986, J. Geophys. Res., 94(A6), 6763-6770, 1989.

Sahai, Y., Bittencourt, J. A., Teixeira, N. R., and Takahashi, H.: Plasma irregularities in the tropical F-region detected by OI $7774 \mathrm{~nm}$ and $6300 \mathrm{~nm}$ nightglow measurements, J. Geophys. Res., 86(A5), 3496-3500, 1981.

Sahai, Y., Takahashi, H., Fagundes, P. R., Clemesha, B. R., Teixeira, N. R., and Bittencourt, J. A. A.: Observations of thermospheric Neutral Wind at $23^{\circ}$ S, Planet. Space Sci., 40, 767-773, 1992.

Sahai, Y., Fagundes, P. R., and Bittencourt, J. A.: Transequatorial
F-region ionospheric plasma bubbles: solar cycle effects, J. Atmos. Terr. Phys., 62, 1377-1383, 2000.

Santana, D. C., Sobral, J. H. A., Takahashi, H., and Taylor, M. J.: Optical studies of the ionospheric irregularities over the Brazilian region by nocturnal images of the OI $630 \mathrm{~nm}$ emission, Adv. Space Res., 27 (6/7), 1207-1212, 2001.

Taylor, M. J., Eccles, J. V., LaBelle, J., and Sobral, J. H. A.: High resolution OI $(630 \mathrm{~nm})$ image measurements of F-region depletion drifts during the Guara campaign, Geophys. Res. Lett., 24 1699-1702, 1997.

Tinsley, B. A.: Field aligned observations of transequatorial bubbles in the tropical F-region, J. Atmos. Terr. Phys., 44, 547-557, 1982.

Tinsley, B. A., Rohrbaugh, R. P., Hanson, W. B., and Broadfoot, A. L.: Images of transequatorial F-region bubbles in 630- and 777nm emissions compared with satellite measurements, J. Geophys. Res., 102(A2), 2057-2077, 1997.

Tsunoda, R. T.: On the Generation and Growth of Equatorial Backscatter Plumes, 2. Structuring Of The West Walls of Upwellings, J. Geophys. Res. 88, 4869-4874, 1983.

Valladares, C. E., Meriwether, J. W., Sheehan, R., and Biondi, M. A.: Correlative study of neutral winds and scintillation drifts measured near the magnetic equator, J. Geophys. Res., doi: 10.1029/2001JA000042, 2002.

Weber, E. J., Buchau, J., Eatther, R. H., and Mende, S. B.: Northsouth aligned equatorial airglow depletions, J. Geophys. Res., 83, 712-716, 1978.

Weber, E. J., Buchau J., and Moore, J. G.: Airborne Studies Of Equatorial F-Layer Ionospheric Irregularities, J. Geophys. Res., 85, 4631-4641, 1980.

Woodman, R. F.: East-west ionospheric drifts at the magnetic equator, Space Res., 12, 968-974, 1972.

Zalesak, S. T., Ossakow, S. L., and Chaturvedi, P. K.: Nonlinear equatorial Spread F: The effect of neutral winds and background Pedersen conductivity, J. Geophys Res. 87, 151-166, 1982. 